\title{
Variabilidade genética de búfalos em rebanho-núcleo com base na análise de pedigree
}

[Genetic variability in water buffalo from nucleous herd by pedigree analysis]

\author{
C.R. Marcondes ${ }^{1}$, P.A. Vozzi $^{2}$, B.R.N. Cunha ${ }^{3}$, R.B. Lôbo $^{2}$, C.V. Araújo ${ }^{4}$, J.R.F. Marques ${ }^{1}$ \\ ${ }^{1}$ Embrapa Amazônia Oriental \\ Travessa Dr. Enéas Pinheiro, s/n \\ 66095-100 - Belém, PA \\ ${ }^{2}$ Associação Nacional de Criadores e Pesquisadores - ANCP - Ribeirão Preto, SP \\ ${ }^{3}$ Universidade Federal Rural da Amazônia - Belém, PA \\ ${ }^{4}$ Universidade Federal de Mato Grosso - Sinop, MT
}

\begin{abstract}
RESUMO
Parâmetros baseados na probabilidade de origem do gene foram usados para descrever a variabilidade em uma população de búfalos da Embrapa Amazônia Oriental. A magnitude dos resultados foi de média a baixa (por volta de 20 animais), sugerindo que poucos fundadores contribuiriam para a formação da população. Dentre os 20 ancestrais que mais aportam genes aos machos - representando ao todo $71 \%$ dos alelos -, 39\%, 26\% e 5\%, respectivamente, são as contribuições marginais das raças Murrah e Mediterrâneo e seus mestiços. Para as fêmeas, em que os 20 ancestrais aportam 67,5\% dos genes, $42 \%$ e $26 \%$, respectivamente, são as contribuições marginais das raças Murrah e Mediterrâneo.
\end{abstract}

Palavras-chave: Bubalus bubalis, contribuição marginal, estratégia de acasalamento, estrutura da população

\begin{abstract}
Parameters based on the probability of gene origin were used to describe genetic variability in a buffalo population from the Embrapa Amazônia Oriental, Belém, Pará, Brazil. The parameters generated medium to low values (around 20 animals) and suggested low founder representativeness. From the 20 ancestors that gave more genes to males (with $71 \%$ of alleles), genetic contributions were 39\%, 26\%, and $5 \%$, respectively, for Murrah, Mediterraneo, and crossbreds. For females, these values were $42 \%$ and $26 \%$ for Murrah and Mediterraneo breeds.
\end{abstract}

Keywords: Bubalus bubalis, marginal contribution, mating strategies, population structure

\section{INTRODUÇÃO}

A Embrapa Amazônia Oriental desenvolveu trabalhos e pesquisas nas áreas de produção e melhoramento genético dos bubalinos, entre as décadas de 60 e 90, como os estudos de comportamento produtivo desses animais na região e de cruzamento absorvente para a raça Murrah, aprimorando-a e dando-lhe o perfil de produção desejado. Para isso, utilizou-se uma base de fêmeas das raças Mediterrâneo, Jafarabadi e poucos exemplares da raça Murrah, existentes nas estações experimentais de Belém e

Recebido em 2 de dezembro de 2009

Aceito em 14 de junho de 2010

E-mail: cimarcon@cpatu.embrapa.br do Baixo Amazonas, no Estado do Pará. Posteriormente, foram realizadas pesquisas com sêmen importado da Bulgária e da Itália, sendo este disponibilizado aos criadores de vários estados brasileiros, entre eles, Pará, Ceará, São Paulo, Paraná e Rio Grande do Sul, como forma de delineamento de um programa de melhoramento genético animal, incluindo um teste de progênie nacional. Com isso, a base genética do rebanho está estruturada, principalmente, por animais provenientes do cruzamento absorvente das fêmeas da raça Mediterrâneo ou mestiças com machos da raça Murrah, sendo estes de origem nacional ou não. 
O aumento da endogamia, segundo Boichard et al. (1997), pode ser usado para derivar o tamanho efetivo de uma população. No entanto, este método reflete principalmente os efeitos a longo prazo da seleção e, ainda, é muito sensível às informações de um pedigree incompleto. Uma alternativa complementar seriam os parâmetros baseados na probabilidade de origem do gene, sendo que o número efetivo de fundadores e o número efetivo de genomas remanescentes são comumente utilizados em populações selvagens, porém menos frequentes nos estudos de animais domésticos. No entanto, encontram-se estudos em várias espécies domésticas e de diferentes raças, como em bovinos (Faria et al., 2002; Vercesi Filho et al., 2002; Pereira et al., 2005; Vozzi et al., 2006; Hammami et al., 2007; Vozzi et al., 2007; Martínez et al., 2008), em equinos (Costa et al., 2005), em ovinos (Goyache et al., 2003), em suínos (Toro et al., 2000) e até mesmo em jumentos (Gutiérrez et al., 2005), com base em algum tipo de análise de pedigree. Para bubalinos, no entanto, o único estudo encontrado na literatura até o momento é o de Malhado et al. (2008), no qual foram calculados o tamanho efetivo e a endogamia na raça Mediterrâneo.

A Embrapa Amazônia Oriental, vale ressaltar, caracterizou-se por muitos anos como fornecedora de material genético como resultado de seleção intrarrebanho, para vários estados brasileiros, o que, consequentemente, permite estabelecer relações de parentesco entre animais submetidos a diversos sistemas de produção. Com base nesta possibilidade, foram submetidos projetos às fontes de financiamento com foco nos estudos da estrutura genética dos rebanhos paraenses (incluindo-se o rebanho da Embrapa Amazônia Oriental) a fim de verificar a variabilidade genética existente e, assim, ter ideia exata de como ocorreu o fluxo gênico na população para, futuramente, averiguar a existência ou não de famílias ou linhagens com aptidões específicas de produção. Além disso, biotécnicas reprodutivas e métodos de predição de valores genéticos, os quais são responsáveis por incrementos consideráveis nas características de importância econômica, favorecem, por outro lado, o uso de poucos pais, limitando a contribuição genética. Sabendo-se desse fato e, por iniciar um programa de melhoramento genético para bubalinos de dupla-aptidão no Estado do Pará, os resultados deste tipo de estudo permitem o gerenciamento da perda de variabilidade genética, por meio do controle dos níveis de endogamia e da manutenção de alelos fundadores desejáveis.

O objetivo deste trabalho foi obter a indicação dos ancestrais, via análise de pedigree, como primeira sinalização das famílias mais importantes do rebanho da Embrapa, o qual encontra-se inserido no programa de melhoramento de búfalos, parceria Associação Paraense de Criadores de Búfalos, Embrapa Amazônia Oriental e Universidade Federal Rural da Amazônia.

\section{MATERIAL E MÉTODOS}

Foram utilizadas informações genealógicas de 776 animais, nascidos entre 1957 e 2004, sendo 308 machos e 468 fêmeas; 158 animais da raça Murrah, 237 da raça Mediterrâneo e 381 cruzados Murrah x Mediterrâneo, pertencentes ao rebanho da Embrapa Amazônia Oriental, o qual apresenta genes disseminados por vários estados brasileiros, seja por meio de animais vendidos em leilões, por sêmen ou pelo teste de progênie ocorrido na década de 90.

Para descrever a variabilidade genética, foram utilizados parâmetros baseados na probabilidade de origem do gene. Estes parâmetros são: número efetivo de fundadores $(\mathrm{Nf})$, número efetivo de ancestrais ( $\mathrm{Na}$ ) e número de genomas remanescentes $(\mathrm{Ng})$. Animais fundadores são aqueles de genealogia desconhecida. Os parâmetros foram calculados como descritos a seguir, de acordo com Vozzi et al. (2007):

$\mathrm{Nf}=1 / \Sigma\left(\mathrm{p}^{2} \mathrm{i}\right)$, em que pi é a proporção de alelos na população referência devido ao fundador $\mathrm{i}$;

$\mathrm{Na}=1 / \Sigma\left(\mathrm{p}^{2} \mathrm{k}\right)$, em que pk é a contribuição marginal do ancestral k na população;

$\mathrm{Ng}=1 / \Sigma\left(\mathrm{p}^{2} \mathrm{i} / \mathrm{ri}\right)$, em que ri é a proporção esperada de alelos do fundador i que poderá permanecer na população referência.

Utilizou-se o software PEDIG®/2002 para a obtenção dos parâmetros populacionais e o cálculo do intervalo de gerações em quatro caminhos gaméticos. Os resultados estão descritos por sexo e raça. A Fig. 1 foi formatada em Excel for Windows/2003. 


\section{RESULTADOS E DISCUSSÃO}

$\mathrm{Na}$ Tab. 1, apresenta-se a variabilidade genética do rebanho estudado, representada por Nfun, Nf, $\mathrm{Ng}$, tamanho da população referência (com base nos animais nascidos entre 1998 e 2004), contribuição marginal do(a) reprodutor(a) que aporta mais genes e contribuição marginal dos 20 ancestrais que mais contribuíram com genes, como resultado da análise de pedigree.

Tabela 1. Número de fundadores (Nfun), número efetivo de fundadores (Nf), número de genomas remanescentes $(\mathrm{Ng})$, tamanho da população referência, contribuição marginal (um ancestral) e contribuição marginal (20 ancestrais) na população de bubalinos estudada (média) e por sexo (machos e fêmeas)

\begin{tabular}{lccc} 
& Média & Machos & Fêmeas \\
\hline Nfun & 82 & 83 & 81 \\
$\mathrm{Nf}$ & 24 & 22 & 26 \\
$\mathrm{Ng}$ & 21 & 20 & 23 \\
População referência & 212 & 111 & 101 \\
Contribuição marginal (1 ancestral), em \% & 9,4 & 9,5 & 9,4 \\
Contribuição marginal (20 ancestrais), em \% & 69,1 & 70,8 & 67,5 \\
\hline
\end{tabular}

Detectaram-se, aproximadamente, 80 animais fundadores, sendo que 25 deles efetivamente aportaram genes à população e 20 fundadores contribuíram com, aproximadamente, $70 \%$ dos genes. A endogamia média do rebanho estudado encontra-se abaixo de $0,50 \%$. Os intervalos médios entre gerações para as passagens gaméticas pai-filho e pai-filha foram semelhantes e iguais a 3,33 anos ou cerca de 40 meses. O intervalo de gerações para mãe-filho foi igual a 4,81 anos ou aproximadamente 58 meses e, na linha gamética de mãe-filha, igual a 4,56 anos ou por volta de 55 meses. Estes valores foram mais baixos que os encontrados para raças bovinas no Brasil, como as raças Sindi (Faria et al., 2001) e Tabapuã (Vercesi Filho et al., 2002) e para a raça Sahiwal australiana (Herron, 1978), os quais foram acima de seis anos. Malhado et al. (2008) obtiveram os seguintes resultados para a raça Mediterrâneo: 11,2 $\pm 3,7$ (pai-filho), 12,1 $\pm 3,9$ (pai-filha), 9,6 $\pm 4,8$ (mãe-filho) e 10,6 $\pm 4,6$ (mãe-filha). Além dos argumentos utilizados pelos autores quanto ao longo período entre gerações, como a longa vida produtiva e a necessidade de crescimento do rebanho, os valores refletiriam, também, a baixa oferta de touros melhoradores e o pouco estímulo ao uso de touros jovens, o que levaria ao incremento do ganho genético intrarrebanho, e aos programas de melhoramento, ainda incipientes, no país. O fato de o rebanho da Embrapa Amazônia Oriental ser fornecedor de animais para vários rebanhos também possibilitaria o ciclo produtivo mais rápido, por meio da venda de animais, do descarte e da reposição de novilhas, diferenciado dos demais rebanhos bubalinos comerciais.

Os valores apresentados na Tab. 1 podem ser considerados de baixa magnitude. Para o gado negro japonês, Honda et al. (2006) observaram 74 animais para $\mathrm{Nf}$ e somente cinco para $\mathrm{Ng}$. Em cavalos Andaluz, Valera et al. (2005) encontraram $\mathrm{Nf}$ de 40 e somente seis ancestrais sendo responsáveis por $50 \%$ da variabilidade genética na raça. Ao estudarem três raças italianas da região de Toscana, Pérez Torrecillas et al. (2002) observaram valor mais baixo de $\mathrm{Ng}$ $(10,1)$ na raça Mucca Pisana do que nas raças Chianina $(53,9)$ e Maremmana $(79,6)$, tendo a primeira, aproximadamente, $50 \%$ menos variabilidade genética nos 1231 animais estudados que nos 776 animais considerados no rebanho da Embrapa Amazônia Oriental.

Quanto aos resultados dos 20 ancestrais mais importantes, ou seja, acima de $2 \%$ de contribuição marginal (Tab. 2), para os machos da população em estudo, 10 são machos puros, seis da raça Murrah e quatro da Mediterrâneo e 10 são fêmeas, três da Murrah, três da Mediterrâneo e quatro são mestiças Murrah x Mediterrâneo. Dentre os fundadores mais importantes, nos machos, estão os quatro touros importados, dois Murrah e dois Mediterrâneos, utilizados no teste de progênie da década de 90 , mostrando a fixação de seus alelos no rebanho da Embrapa Amazônia Oriental. Outra questão a ser destacada é o fato de os touros ancestrais Murrah apresentarem igual proporção de filhos 
puros e mestiços, enquanto todos os touros Mediterrâneos tiveram filhos puros. Para as fêmeas, dos 20 ancestrais mais importantes, 12 são touros, oito da raça Murrah e quatro da raça Mediterrâneo. Uma explicação para este fato pode ser a manutenção de filhas mestiças para o cruzamento absorvente, descendentes de touros Murrah.

Pode-se destacar a presença do macho I, da raça Murrah, como pai de fêmeas do rebanho, aportando $4,7 \%$ de genes. Um estudo como este permitirá que sejam relacionadas características produtivas dos ancestrais e seus descendentes. Marcondes et al. (2007) observaram que, dentre os touros melhor classificados quanto à característica stayability, dos sete ancestrais que aportaram o maior percentual de genes, cinco eram da variedade mocha. Outra aplicação é a identificação de linhas para direcionamento da seleção de pais de touros ou mães de touros, como relatado por Magnabosco et al. (1997) sobre a utilização do acasalamento em linha na formação de diferentes linhagens na raça Nelore.

Tabela 2. Ancestral (codificado), sexo, raça $(\mathrm{Mu}=$ Murrah e Med = Mediterrâneo) e contribuição marginal (em \%), para cada sexo

\begin{tabular}{cccccccc}
\hline & \multicolumn{2}{c}{ Machos } & \multicolumn{5}{c}{ Fêmeas } \\
Ancestral & Sexo & Raça & $\begin{array}{c}\text { Contribuição } \\
\text { marginal (\%) }\end{array}$ & Ancestral & Sexo & Raça & $\begin{array}{c}\text { Contribuição } \\
\text { marginal (\%) }\end{array}$ \\
\hline A & M & Mu & 9,5 & C & M & Mu & 9,4 \\
B & M & Med & 8,8 & A & M & Mu & 8,3 \\
C & M & Mu & 8,6 & H & M & Med & 7,4 \\
D & M & Med & 7,9 & B & M & Med & 7,2 \\
E & M & Mu & 7,0 & I & M & Mu & 4,7 \\
F & M & Mu & 6,9 & F & M & Mu & 4,5 \\
G & M & Med & 3,6 & E & M & Mu & 4,0 \\
H & M & Med & 2,5 & D & M & Med & 3,2 \\
& & & & J & M & Mu & 2,7 \\
& & & & K & M & Mu & 2,5 \\
& & & & F & Mu & 2,2 \\
\hline
\end{tabular}

Dentre os 20 ancestrais que mais aportam genes aos machos (ao todo 71\% dos alelos), 39\%, 26\% e $5 \%$, respectivamente, são as contribuições marginais das raças Murrah, Mediterrâneo e mestiços. Para as fêmeas, em que os 20 ancestrais aportam $67,5 \%$ dos genes, $42 \%$ e $26 \%$, respectivamente, são as contribuições marginais das raças Murrah e Mediterrâneo (Fig. $1)$.

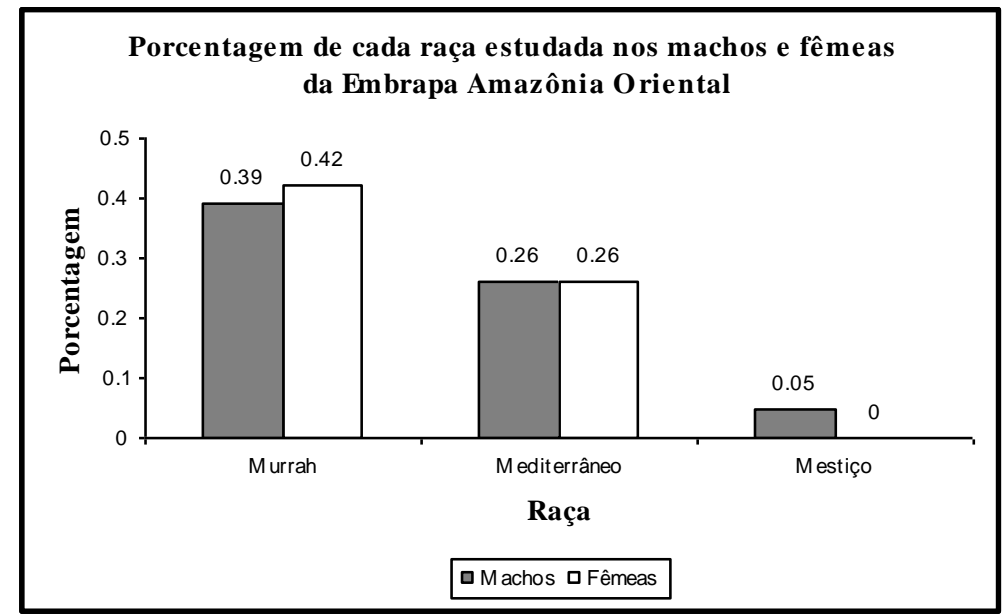

Figura 1. Porcentagem das raças Murrah, Mediterrâneo e mestiço Murrah x Mediterrâneo na população de búfalos da Embrapa Amazônia Oriental. 
O pequeno número de animais fundadores evidencia a necessidade de monitoramento da endogamia do rebanho estudado, a busca de ferramentas de controle ou até mesmo a introdução de animais que não possuam parentesco direto com os 20 principais ancestrais identificados neste estudo. Malhado et al. (2008) concluíram que, para o aumento dos ganhos genéticos, é necessária a redução do intervalo de geração, o aumento do tamanho efetivo, o uso de reprodutores avaliados geneticamente e o controle dos acasalamentos, o que corrobora os resultados obtidos no rebanho da Embrapa Amazônia Oriental.

$\mathrm{O}$ número de genomas remanescentes apresentou-se baixo em relação ao número de fundadores, indicando que possivelmente muitos alelos foram perdidos ao longo dos anos e, consequentemente, a variabilidade genética disponível e necessária a um programa de melhoramento acabou prejudicada. Com isso, ressalta-se, mais uma vez, a importância do monitoramento da variabilidade genética e o controle da endogamia.

\section{CONCLUSÕES}

As raças Murrah e Mediterrâneo aportaram percentuais semelhantes de genes nos machos e fêmeas, no entanto os machos receberam contribuição também das fêmeas mestiças, já que, na população estudada, foram realizados cruzamentos absorventes para a raça Murrah. Sabendo-se desse fato e por iniciar um programa de melhoramento genético para bubalinos de dupla-aptidão, os resultados desse tipo de estudo permitirão o gerenciamento dos recursos genéticos, por meio do controle dos níveis de endogamia e da manutenção de alelos fundadores desejáveis.

\section{AGRADECIMENTOS}

Ao $\mathrm{CNPq}$ (Projeto Universal - Processo: 470281/2007-3) e à FAPESPA (Projeto JP Processo: 035/2008), pela concessão de recursos financeiros, e à ANCP, pelo auxílio nas análises de dados.

\section{REFERÊNCIAS BIBLIOGRÁFICAS}

BOICHARD, D.; MAIGNEL, L.; VERRIER, E. The value of using probabilities of gene origin to measure genetics variability in a population. Genet. Sel. Evol., v.29, p.5-23, 1997.

COSTA, M.D.; BERGMANN, J.A.G.; RESENDE, A.S.C. et al. Análise temporal da endogamia e do tamanho efetivo da população de equinos da raça Mangalarga Marchador. Arq. Bras. Med. Vet. Zootec., v.57, p.112-119, 2005.

FARIA, F.J.C.; VERCESI FILHO, A.E.; MADALENA, F.E. et al. Parâmetros populacionais do rebanho Sindi registrado no Brasil. Rev. Bras. Zootec., v.30, p.1989-1994, 2001.

FARIA, F.J.C.; VERCESI FILHO, A.E.; MADALENA, F.E. et al. Estrutura populacional da raça Nelore Mocho. Arq. Bras. Med. Vet. Zootec., v.54, p.501-509, 2002.

GOYACHE, F.; GUTIÉRREZ, J.P.; FERNÁNDEZ, I. et al. Using pedigree information to monitor genetic variability of endangered populations: the Xalda sheep breed of Asturias as an example. J. Anim. Breed. Genet., v.120, p.95-105, 2003.

GUTIÉRREZ, J.P.; MARMI, J.; GOYACHE, F. et al. Pedigree information reveals moderate to high levels of inbreeding and a weak population structure in the endangered Catalonian donkey breed. J. Anim. Breed. Genet., v.122, p.378-386, 2005.

HAMMAMI, H.; CROQUET, C.; STOLL, J. et al. Genetic diversity and joint-pedigree analysis of two importing Holstein populations. J. Dairy Sci., v.90, p.3530-3541, 2007.

HERRON, N.D. The breed structure and genetic analysis of the pedigree Sahiwal breed in Australia. Aust. J. Agric. Res., v.29, p.381-393, 1978.

HONDA, T.; FUJII, T.; NOMURA, T. et al. Evaluation of genetic diversity in Japanese Brown cattle population by pedigree analysis. $J$. Anim. Breed. Genet., v.123, p.123-129, 2006.

MAGNABOSCO, C. de U.; CORDEIRO, C.M.T.; TROVO, J.B.F. et al. Catálogo de linhagens do germoplasma zebuíno: raça Nelore. Brasília: Embrapa-Cenargen, 1997. 52p. (Documento 23). 
MARCONDES, C.R.; VOZZI, P.A.; ARAÚJO, R.O. et al. Contribuição dos efeitos de genearcas e de famílias sobre a probabilidade de permanência em rebanhos da raça Nelore. Arq. Bras. Med. Vet. Zootec., v.59, p. 977-982, 2007.

MALHADO, C.H.M.; RAMOS, A.A.; CARNEIRO, P.L.S. et al. Melhoramento e estrutura populacional em bubalinos da raça Mediterrâneo no Brasil. Pesq. Agropec. Bras., v.43, p.215-220, 2008.

MARTÍNEZ, R.A.; GARCÍA, D.; GALLEGO, J.L. et al. Genetic variability in Colombian Creole cattle populations estimated by pedigree information. J. Anim. Sci., v.86, p.545-552, 2008.

PEREIRA, M.C.; MERCADANTE, M.E.Z.; ALBUQUERQUE, L.G. et al. Estimativa de ganho genético a partir de diferenciais de seleção e parâmetros populacionais em um rebanho Caracu. Rev. Bras. Zootec., v.34, p.2245-2252, 2005.

PÉREZ TORRECILLAS， C.; BOZZI， R.; NEGRINI, R. et al. Genetic variability of three Italian cattle breeds determined by parameters based on probabilities of gene origin. J. Anim. Breed. Genet., v.119, p.274-279, 2002.
TORO, M.A.; RODRIGAÑEZ, J.; SILIO, L. et al. Genealogical analysis of a closed herd of Black Hairless Iberian pigs. Conserv. Biol., v.14, p.1843-1851, 2000.

VALERA, M.; MOLINA, A.; GUTIERREZ, J.P. et al. Pedigree analysis in the Andalusian horse: population structure, genetic variability and influence of the Carthusian strain. Liv. Prod. Sci., v.95, p.57-66, 2005.

VERCESI FILHO, A.E.; FARIA, F.J.C.; MADALENA, F.E. et al. Estrutura populacional do rebanho Tabapuã registrado no Brasil. Arq. Bras. Med. Vet. Zootec., v.54, p.609-617, 2002

VOZZI, P.A.; MARCONDES, C.R; MAGNABOSCO, C.U. et al. Structure and genetic variability in Nellore (Bos indicus) cattle by pedigree analysis. Genet. Mol. Biol., v.29, p.482-485, 2006.

VOZZI, P.A.; MARCONDES, C.R; BEZERRA, L.A.F. et al. Pedigree analyses in the Breeding Program for Nellore Cattle. Genet. Mol. Res., p.1044-1050, 2007. 